\title{
Pterion: Morphometry and Surgical Significance
}

\section{Vimal Gupta ${ }^{1}$, Anshu Sharma ${ }^{* 2}$, Kanchan Kapoor ${ }^{3}$.}

${ }^{1}$ Demonstrator Department of Anatomy Government Medical College and Hospital Chandigarh, Punjab, India.

2 Professor, Department of Anatomy Government Medical College and Hospital Chandigarh, Punjab, India.

${ }^{3}$ Professor, Department of Anatomy Government Medical College and Hospital Chandigarh, Punjab, India.

\section{ABSTRACT}

Introduction: Pterion is a H-Shaped formation of sutures and cranio-metric point on the lateral side of skull. It is marked by the junction of frontal, parietal, greater wing of sphenoid \& squamous temporal bone.

Objective: The study is aimed to determine prevalence of types of pterions, presence of epipteric bone. We also tried to find pterion's relationship with anterior branch of middle meningeal artery

Materials and methods: Study was done in department of Anatomy, GMCH-32, Chandigarh on 40 adult dried skulls without calvaria, of unknown age, gender and race. The skulls with broken lateral wall were excluded. Skulls were examined for 1 . A. prevalence of pterion shape B. Prevalence of bilaterality of similar shape of pterion. C. Prevalence of unilateral variation of pterion on two sides of skull. 2. Epipteric bone A. Presence of epipteric bone B. relation to the suture on both sides. 3. Distance of pterion center point to frontozygomatic suture and upper border of zygomatic arch. 4. relationship of pterion on external and internal surface of skull and on inner side its relationship with anterior branch of Middle meningeal artery.

Observations: In the present study 3 types of pterions i.e., Sphenoparietal, stellate, frontotemporal were observed. Sphenoparietal was found to be present bilaterally $40 \%$ on both sides. Frontotemporal \& stellate were $2.5 \%$. Sphenoparietal type of pterion was $55 \%$ on right side $\& 67.5 \%$ on left side. frontotemporal type of pterion was $5 \%$ on right side $\& 2.5 \%$ on left side, stellate type was $7.5 \%$ on right side $\& 2.5 \%$ on left side. epipteric bone were present in pterion on right side in $32.5 \%$ \& on left side $27.5 \%$. Pterion was lying approximately $3.5 \mathrm{~cm}$ above the zygomatic arch and $2.83 \mathrm{~cm}$ behind the posterior margin of frontozygomatic suture.

Conclusion: in our study the commonest type of pterion shape was Sphenoparietal. This type was most common to be present bilaterally. Epipteric bone was found in Sphenoparietal type both unilaterally \& bilaterally. The anterior branch of MMA was closest and farthest in stellate type.

KEY WORDS: Pterion, Middle meningeal artery, sphenopalatine, stellate, frontotemporal.

Corresponding Author: Dr Anshu Sharma, Professor Department of Anatomy Government Medical College and Hospital Chandigarh, 160030 Mob: 9646121530

E-Mail: anshusharma_01@yahoo.co.in

Access this Article online

\section{Quick Response code}

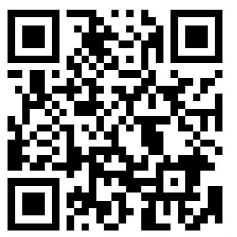

DOI: $10.16965 /$ ijar.2021.185

\begin{tabular}{|c|c|c|}
\hline \multicolumn{3}{|c|}{ Journal Information } \\
\hline \multicolumn{3}{|c|}{$\begin{array}{l}\text { International Journal of Anatomy and Research } \\
\text { ISSN (E) 2321-4287 | ISSN (P) 2321-8967 } \\
\text { https://www.ijmhr.org/ijar.htm } \\
\text { DOI-Prefix: https://dx.doi.org/10.16965/ijar } \quad \text { (cc) E ET-ME-8H }\end{array}$} \\
\hline \multicolumn{3}{|c|}{ Article Information } \\
\hline $\begin{array}{l}\text { Received: } 01 \text { Nov } 2021 \\
\text { Peer Review: } 02 \text { Nov } 2021\end{array}$ & $\begin{array}{l}\text { Accepted: } 04 \text { Jan } \\
\text { Published (O): } 05 \\
\text { Published (P): } 05\end{array}$ & $\begin{array}{l}2 \\
r 2022 \\
2022\end{array}$ \\
\hline
\end{tabular}

\section{INTRODUCTION}

Pterion is an important landmark for surgeons, neurosurgeons as well as anatomists on the lateral side of skull. It is marked by a $\mathrm{H}$-Shaped formation of sutures in the floor of temporal fossa and is formed by the junction of frontal, parietal, greater wing of sphenoid \& squamous temporal bone [1]. 
In human infant's skull, Pterion is site of anterolateral fontanelle. Which closes in about third month post birth. neurosurgeons mark the pterion two fingers superior to the zygomatic arch and a thumb's breadth posterior to the frontal process of the zygomatic bone [2-4].

The pattern of bone articulation at pterion however can be variable in different individuals. Sometimes a small sutural bone or epipteric bones may be present within any of the sutures forming the pterion. It is an important clinical landmark used by maxillofacial surgeons also. Calvaria is thin at this point and gets fractured easily in head injuries. Pterion is related on the inner side of skull to the anterior branch of middle meningeal artery, the lateral sulcus of brain, and Broca's motor speech area. Any lateral blow on the skull can damage anterior branch of middle meningeal artery resulting in extra dural hematoma. This extra dural hematoma is usually evacuated by creating burr holes on pterional site for decompressing the brain tissue. So, knowledge about the location of the anterior branch of the middle meningeal artery is important for accuracy regarding the position of the burr holes to evacuate extradural hematoma caused due to injury to middle meningeal vessels [5-7].

\section{MATERIALS AND METHODS}

Present study is based on observations on 40 adult dried skulls of unknown age, gender and race. The study is conducted in department of Anatomy, GMCH-32, Chandigarh. Skulls without calvaria were included in the study while with broken lateral wall were excluded. Skulls were examined based on morphology i.e.

1. A. Shape of pterion on both sides and

B. Prevalence of bilaterality of pterion.

C. Prevalence of unilateral variation of pterion on two sides of skull

D. Incidence of pterion shape

2. Epipteric bone

A. Presence of epipteric bone

B. prevalence of presence epipteric bone suture wise on both sides.
3. Distance of pterion center point to frontozygomatic suture and upper border of zygomatic arch.

4. Midpoint of pterion on the internal side of skull and its relationship with anterior branch of Middle meningeal artery.

Externally the center of pterion was determined by drawing a circle of smallest radius connecting all the four bones, a center of which was taken as a center of pterion.

Corresponding mid-point of pterion was marked in the cranial cavity with the help of divider placed vertically and measuring distance from the groove formed by anterior branch of middle meningeal artery.

\section{Parameters:}

1) PF: distance from the center of the pterion to the mid-point of the frontozygomatic suture.

2) PT: nearest vertical distance from the center of the pterion to the upper margin of zygomatic arch.

All the reading were taken thrice, and average was calculated. Electronic carbon fiber vernier caliper was used to measure linear distances between the pterion and specific identifiable bony landmarks like frontozygomatic suture and zygomatic arch.

\section{OBSERVATIONS}

Pterion is a weak cranio-metric point on lateral side of skull. It is formed at the junction of four bones i.e., frontal, parietal, temporal \& greater wing of sphenoid \& corresponds to site of anterior fontanelle.

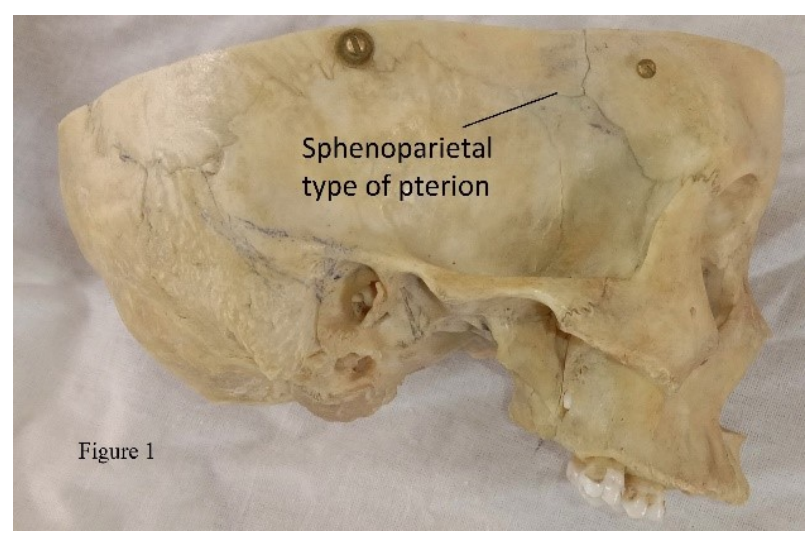

Fig.1: Sphenoparietal type of pterion. 


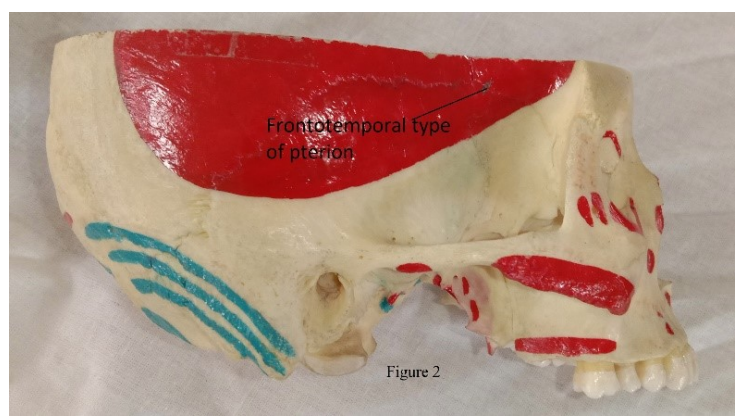

Fig. 2: Temporozygomatic type of pterion.

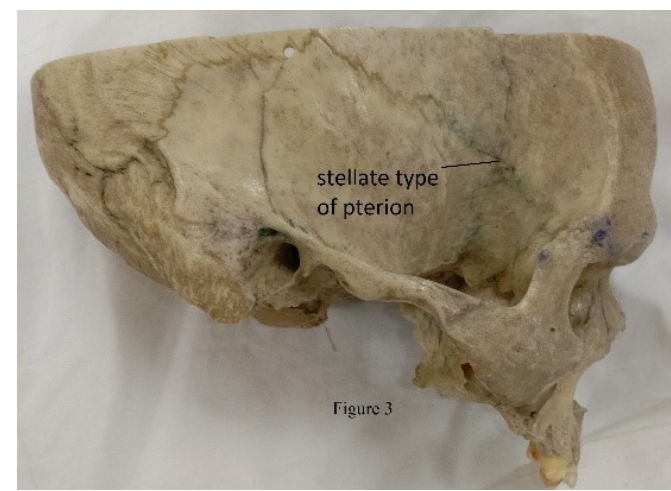

Fig. 3: Stellate variety of pterion.

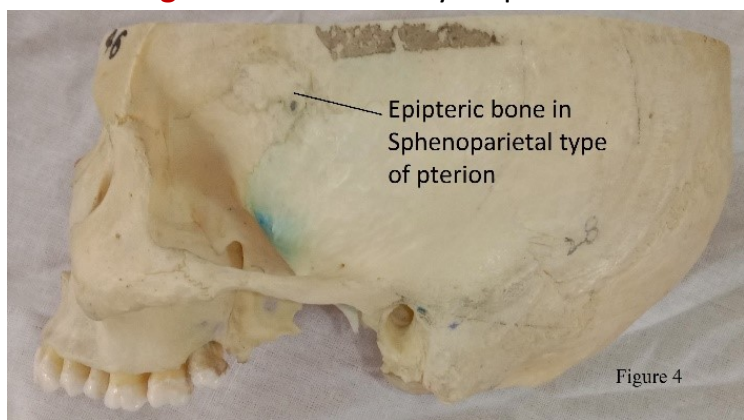

Fig. 4: Epipteric bone(single) present in sphenoparietal type of pterion

Out of 40 skulls, shape of pterion was observed $\&$ it was concluded that sphenoparietal (Figure 1) was commonest variety of pterion. Prevalence was more on left side. Stellate (figure 3 ) was $7.5 \%$ on right side and $2.5 \%$ on left side. Least variety was frontotemporal. (Figure 2) (Tabel1, bar chart 1)

Table 1: Shape of pterion

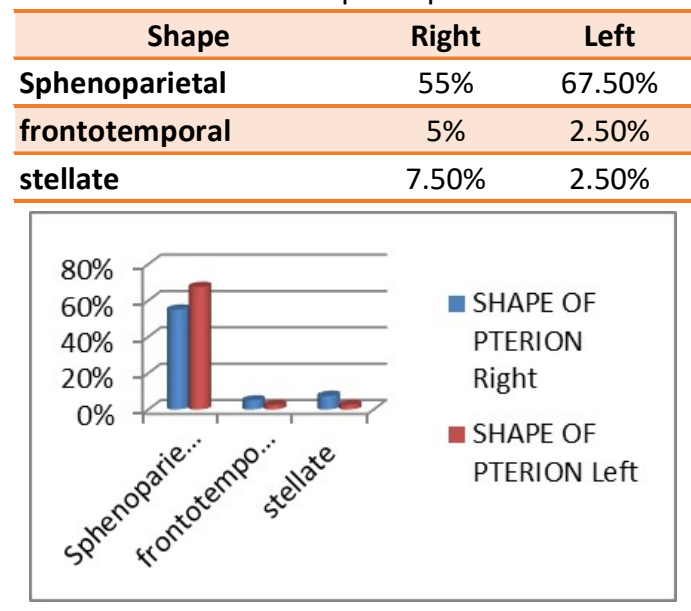

Bar chart 1: \% wise Shape of pterion.
Sphenoparietal was found to be present bilaterally $40 \%$ on both sides. Frontotemporal \& stellate were $2.5 \%$. (Table 2, bar chart 2)

Table 2: Bilateral variation of pterion.

\begin{tabular}{lc}
\hline \multicolumn{1}{c}{ Shape } & Bilaterality \\
\hline Sphenoparietal & $40 \%$ \\
\hline frontotemporal & $2.50 \%$ \\
\hline Stellate & $2.50 \%$ \\
\hline
\end{tabular}

\section{BILATERAL VARIATION OF PTERION}

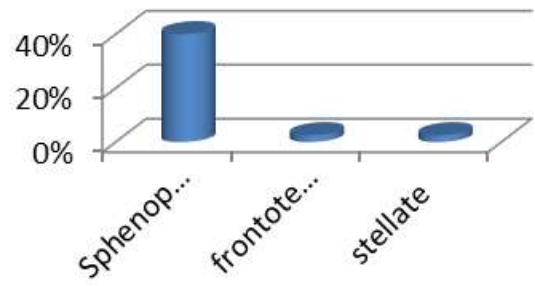

Bar chart 2: \% wise bilateral variation of pterion.

We found that for unilateral variation of pterion, Prevalence was $27.5 \%$ on left side \& $15 \%$ on right side. (Table 3 bar chat 3)

Table 3: Unilateral variation of pterion.

\begin{tabular}{lcc}
\hline \multirow{2}{*}{\multicolumn{1}{c}{ Shape }} & \multicolumn{2}{c}{ Unilaterality } \\
\cline { 2 - 3 } & Right & Left \\
\hline Sphenoparietal & $15 \%$ & $27.50 \%$ \\
\hline frontotemporal & $2.50 \%$ & $0 \%$ \\
\hline stellate & $5 \%$ & $0 \%$ \\
\hline
\end{tabular}

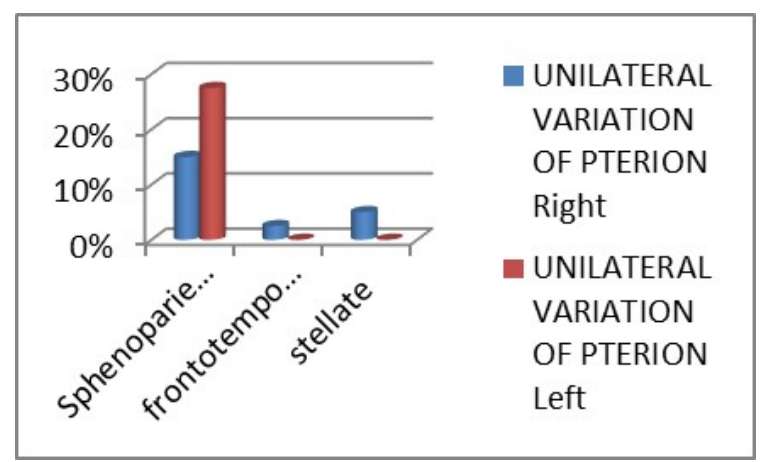

Bar chart 3: \% wise prevalence unilateral variation of pterion.

Epipteric bones or wormian bones were found overall $32 \%$ on right side $\& 27.5 \%$ on left side. Bilaterally $10 \%$. Epipteric bone was more common unilaterally $\&$ on right side. (Table 4 , pie chart 1)

Table 4: Presence of epipteric bone or Wormian bone.

\begin{tabular}{cccccc}
\hline \multirow{2}{*}{$\begin{array}{c}\text { Epipteric } \\
\text { bone }\end{array}$} & \multirow{2}{*}{ Right } & Left & \multirow{2}{*}{ BL } & \multicolumn{2}{c}{ UL } \\
\cline { 2 - 6 } \cline { 4 - 6 } & & & & $\mathbf{R}$ & L \\
\hline
\end{tabular}




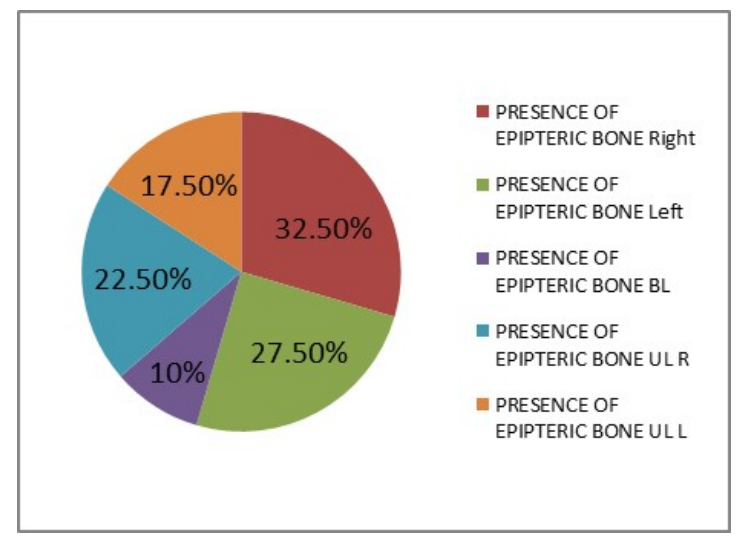

Pie chart 1: \% wise Presence of epipteric bone or Wormian bone.

The average distance of pterion from $F Z$ suture \& ZA. Average distance from FZ suture on both sides were $2.8 \mathrm{~cm}$. its distance from ZA was $3.5 \mathrm{~cm}$ on right $\& 3.4 \mathrm{~cm}$ on left. (Table- 5 bar chart 4)

Table 5: Average distance of pterion from FZ suture \& ZA.

\begin{tabular}{cccc}
\hline \multicolumn{2}{c}{ Frontozygomatic Suture } & \multicolumn{2}{c}{ Zygomatic Arch } \\
\hline Right & Left & Right & Left \\
\hline $28.5775 \mathrm{~mm}$ & $28.27 \mathrm{~mm}$ & $35.99 \mathrm{~mm}$ & $34.8275 \mathrm{~mm}$ \\
\hline
\end{tabular}

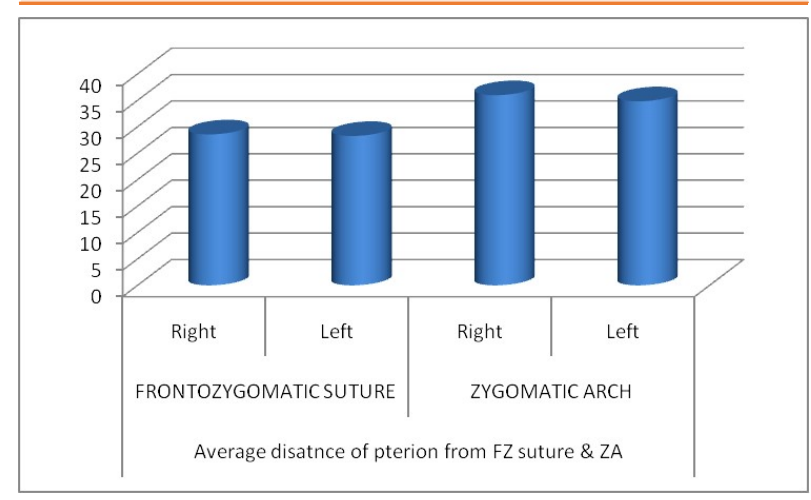

Bar chart 4: Average distance of pterion from FZ suture \& ZA.

The average distance of MMA from pterion measured from cranial cavity. It was measured to be $4.9 \mathrm{~mm}$ on right side $\& 5.13 \mathrm{~mm}$ on left side. (Table-6 bar chart 5)

Table 6: Average distance of MMA from pterion measured from internal side of cranial cavity.

\begin{tabular}{cc}
\hline Right & Left \\
\hline $4.99 \mathrm{~mm}$ & $5.13 \mathrm{~mm}$ \\
\hline
\end{tabular}

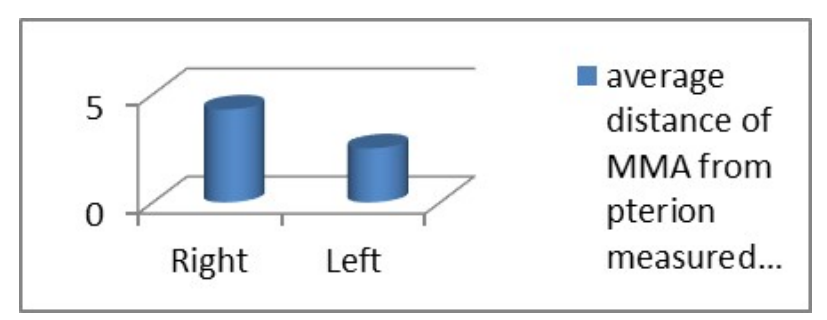

Bar chart 5: Average distance of MMA from pterion measured from inner side of cranial cavity
Table 7: Average distance of mma from pterion measured from cranial cavity in sphenoparietal type bilaterally

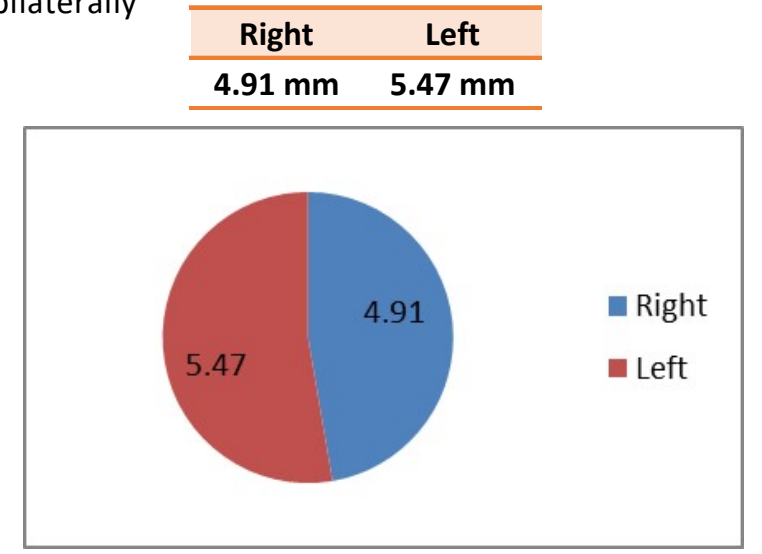

pie chart 2: Average distance of MMA from measured from cranial cavity in sphenoparietal type of pterion. Average distance of MMA from measured from cranial cavity in sphenoparietal type bilaterally.

From, or study it was concluded that average distance of MMA from measured from cranial cavity in sphenoparietal type in right was $4.91 \mathrm{~mm} \& 5.47 \mathrm{~mm}$ in left. (Table-7 pie chart 2)

Table 8: Average distance of MMA from pterion measured from cranial cavity in frontotemporal type.

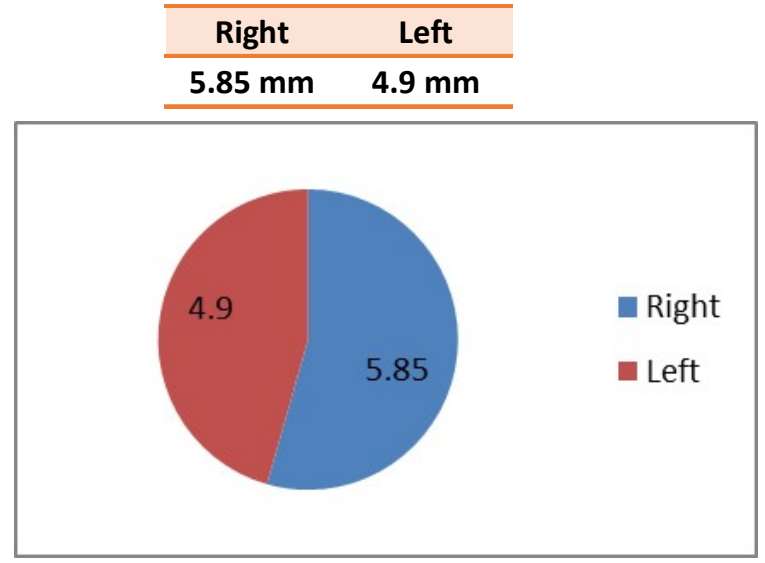

Pie chart 3: Average of MMA from pterion measured from cranial cavity in sphenoparietal type bilaterally.

It was concluded that average distance of MMA from measured from cranial cavity in frontotemporal type in right was $5.85 \mathrm{~mm}$ \& $4.9 \mathrm{~mm}$ in left (table-8 Pie chart 3).

We observed that average distance of MMA from measured from cranial cavity in stellate type in right was $6.13 \mathrm{~mm} \& 5.1 \mathrm{~mm}$ in left. (Table-9, pie chart 4).

Table 9: Average distance of MMA from pterion measured from cranial cavity in stellate type.

\begin{tabular}{cc}
\hline Right & Left \\
\hline $6.13 \mathrm{~mm}$ & $5.1 \mathrm{~mm}$ \\
\hline
\end{tabular}




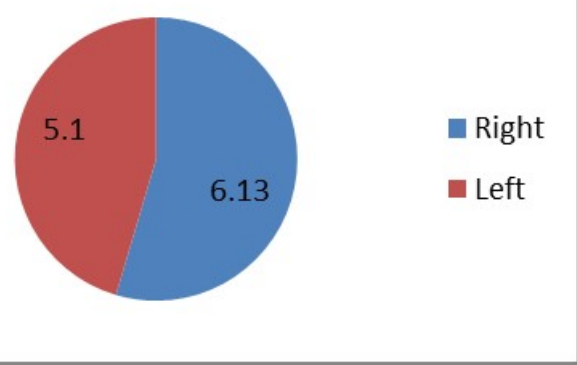

Pie chart 4: Average distance of MMA from measured from cranial cavity in stellate of pterion

The prevalence of epipteric bone in different types of pterions was observed as sphenoparietal type in ratio of $30 \%$ on right $\& 22.5 \%$ on left. No epipteric bone was found on right frontotemporal type \& in 5\% was found on left. in stellate type, it was $2.5 \%$ on right side $\&$ none was found on left side. (Table 10, bar chart 6)

Table 10: Prevalence of epipteric bone in different types of pterion.

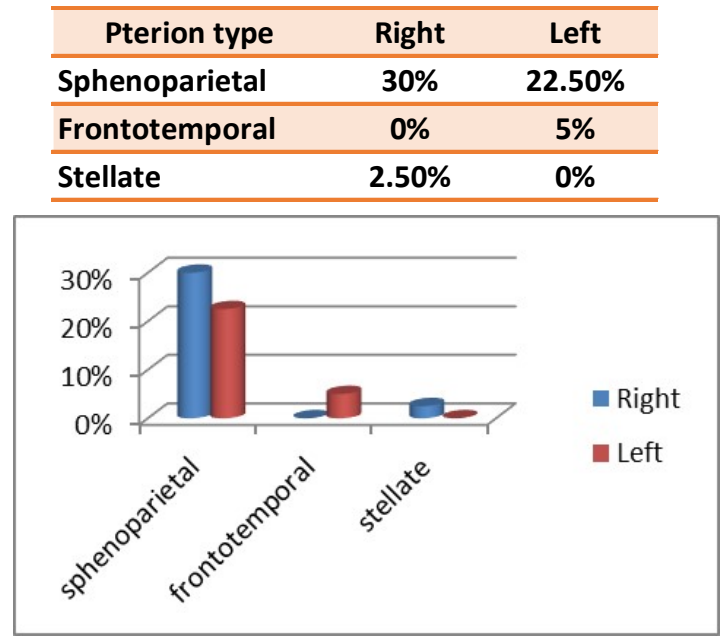

Bar chart 6: \% Wise prevalence of epipteric bone in different types of pterions.

The maximum \& minimum distance of MMA from pterion in stellate type. minimum distance is $2 \mathrm{~mm}$ \& maximum is $11.11 \mathrm{~mm}$. (Table-11 Pie cart 5)

Table 11: Maximum \& minimum distance of MMA in stellate suture.

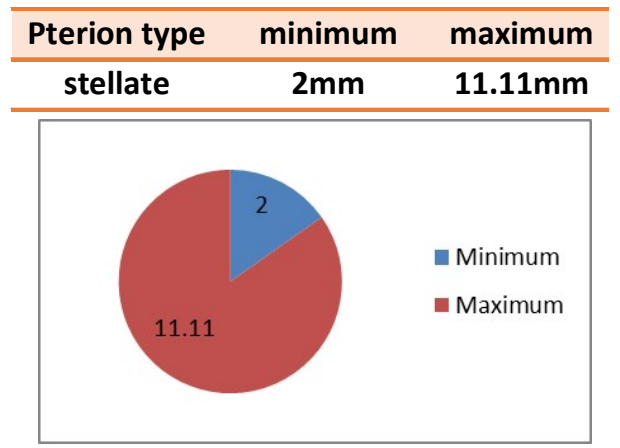

Pie chart 5: Distance of MMA from pterion in stellate type

\section{DISCUSSION}

Pterion is a region in the anterior part of the floor of the temporal fossa where the greater wing of the sphenoid, the parietal, frontal and the squamous temporal bones meet and form a $\mathrm{H}$ shaped suture [1]. It is a commonly used landmark to find the place of anterior division of middle meningeal artery inside [2].

Cranial sutures are fibrous tissue joint between various cranial bones [8]. During the various stages of the life sutures may permit minor movement as in passage through birth canal, the other function attributed to, are shock absorption, brain growth, and prevent of cranial bone separation [8-12].

Cranial vault bones are derived from neural crest and mesenchyme. The development of these skull cap bones proceeds by intramembranous ossification within a layer of mesenchyme, whereas, skull base cartilages are derived from the occipital somites ossify to form the supraoccipital bone. The supraoccipital bone eventually fuses with the membranous interparietal bones to complete the skull posteriorly. The cranial region of mammalian embryos contains the first four somites and all structures rostral to them. The trigeminal crest is the only region rostral to the somites that contributes to skull development. The trigeminal crest also contributes to the development of the neural plate region as well as the neural tube. The trigeminal neural crest cells maintain a separation from the adjacent mesodermal cranial mesenchyme cells during early development. Hox gene plays a major role in early craniofacial patterning and it is inhibitory to the development of the neural crest derived craniofacial skeleton [8,10-13]. There is a relationship between the neural crest-mesoderm tissue boundary and the position of sutures in the skull vault. These sutures act as the neural crest-mesoderm interfaces. During early development, the sides and roof of the skull arise by membranous ossification. This ossification is characterized by needle-like bone spicules that radiate peripherally. Presumptive sutures and fontanels appear at the margins of the frontal, parietal, and occipital bones, during this 
early membranous ossification. The frontal bone, facial sutures, metopic suture, and coronal suture are of neural crest origin. In contrast, the parietal bone, occipital bone, sagittal suture, and lambdoid suture are of mesodermal origin. The rostral neural crest cells act as signal for sutural growth. Sutures develop by a wedge-shaped proliferation of cells at the periphery of the extending bone fields, termed the osteogenic fronts. The osteogenic fronts appear to govern morphogenetic determination of sutural architecture $[8,14]$.

The genetic factors play important role in the growth and maintenance of cranial sutures. Efnb1, FGF-FGFr plays a role in formation and osteogenic growth and differentiation at the sutural margins $[15,16,9]$, Other genetic factors areTWIST1, TGF-â family MSX2, and Sonic Hedgehog (Shh) is expressed in the sutural mesenchyme between proliferating osteoblasts of the frontal and parietal bone edges-separating two bone forming tissues and initiating transcription of Fgfr2 $[8,15,16]$.

Early in ontogeny the cranial sutures are especially affected by the expanding brain, and the neuro capsular matrix as a whole Dura also sends signals for cell proliferation and synthesis [17].

Cranial shape adjusts to the expanding brain by bone deposition at the sutural margins. Cranial growth proceeds perpendicular to each of the major sutures. After the full growth of the brain a period of stasis follows which precedes cranial suture remodeling and fusion [9]. Calvarial suture morphology is also affected biomechanical tensile forces as in untreated hydrocephalus observed compensatory sutural interdigitation. However, neurocranial expansion is not always temporally related to human suture activity and thus, unlikely to influence eventual suture morphology and fusion [9].

To begin with, sutures are straight edges of bone separated by connective tissue. Sutural interdigitation develops as a result and product of tensile, compressive, and shearing forces occurring at the suture site. In general, the longer a suture remains patent before osseous obliteration, the more interdigitated it will become [9] (Cohen and MacLean, 2000; Enlow and Hans, 1996). Masticatory forces may have strong effect on suture morphology and fusion [18]. Data from animal models supports this concept. Experimental evidence hyper muscular murine GDF-8 (Myostatin) knockout model also supports this concept $[19,20]$.

There are four different types of pterions they are the sphenoparietal, frontotemporal, stellate and the epipteric varieties [2].

In a study by [21] on 40 Nigerians and 72 Indians Nigerian population it was observed that three varieties of pterion i.e., sphenoparietal, frontotemporal and stellate were found in both races. The author reported that frequency of sphenoparietal pterion was high in both races (Indians $95.3 \%$, Nigerians $84.79 \%$ ) while the frontotemporal \& stellate was more in Nigerians (10.11\%, 5.06\%). The frequency of epipteric bone is high in Indians (Indians $11.79 \%$, Nigerians $3.79 \%$ ) and is more commonly associated with sphenoparietal pterion. In this study no epipteric bone was associated with stellate pterion in both races. The difference in the distance of pterion from the zygomatic arch is highly significant between two races on both sides. While the distance of pterion from the frontozygomatic suture is insignificant between the two races. 7.author also described frequency of "high Pterion" is more in Nigerians on both sides \&the frequency of "Backward Pterion" is more in Indians on the right side, whereas little more in Nigerians on the left side.

In another study carried on Japanese's 614 skulls. The investigator used 258 skulls of Japanese fetuses ranging from the fourth to the ninth month, 20 skulls of Japanese juveniles from the third month to 17 years of age, and 336 skulls of Japanese adults from 20 to 89 years of age. In this study the incidence of ossification in the fetal sphenoidal fontanelle was $3.6 \%$ on each side. Epipteric bones were observed in more than $10 \%$ of the juvenile and adult skull pterion. In adult skull pterion the most common form was a Sphenoparietal. He further classified them (306 pteria) in to five types, high (119), low (21), and narrow (32) types Another form of this type, a frontal process of the temporal bone without contact 
with frontal bone, was found in five pteria. The Frontotemporal type of pterion contact was classified by the author into two types: One is with a frontal process of the temporal bone (17 pteria), and another is a K-shaped contact referred to as "stellate" (four). The two types were observable in adult skulls of all ages although the fused pteria and fusing epipteric bones were observed in cases over 40 years of age. It was suggested that the pterion formation has two phases, the first occurring before the occlusion of sphenoidal fontanelle, and the second starting after 40 years of age [22].

Asala and Mbajiorgu [23] assessed the variation of pterion articulation in 212 northeastern Nigerian dried skulls. They observed four sutural variants. Sphenoparietal articulation was present in $82.1 \%$, frontotemporal articulation in $23.6 \%$, stenocrotaphia in $1.9 \%$ and epipteric articulation in $5.7 \%$ of the skulls. Symmetry of articulation was predominant in sphenoparietal $(86.7 \%)$, frontotemporal (58.0\%) and stenocrotaphia (100.0\%) articulations. Epipteric articulation was $100.0 \%$ unilateral. In unilateral presence, the right side was predominant for sphenoparietal (65.2\%) and epipteric (66.7\%) variety. Frontotemporal articulation was predominantly seen on the left side (73.9\%).

Saxena R [7] studied two hundred and three skulls of known sex (100 male and 103 female) for the variations of Pterion. They also found Sphenoparietal variety as most common followed by frontotemporal and stellate varieties. The present study has shown separate incidence of Pterion in known male and female skulls of Awadh area.

Mwachaka PM [24]. investigated that the pterion and asterion formation exhibit population-based variations. Ninety human skulls of known gender (51 male, 39 female) were studied by them. They observed four types of pteria were observed: sphenoparietal $(66.7 \%)$, frontotemporal $(15.5 \%)$, stellate (11.1\%) and epipteric (6.7\%). According to them the epipteric type occurred more in females $(10.5 \%)$ than in males $(4.8 \%)$.

Praba [25] studied 50 human crania (100 pteria) of known sex i.e. 40 male and 10 female for the presence of different types of Int J Anat Res 2022, 10(1):8197-05. ISSN 2321-4287 pterions in the skulls of Tamil Nadu. They also found sphenoparietal variety commonest and the frontotemporal the least common. no significant difference between gender was found by them. Each pterion has a little difference their association with the middle meningeal artery and is important for neurosurgeons and forensic anthropologists.

Middle meningeal artery has some vascular markings on the inner surface of the skull. The osseous groove for the middle meningeal artery begins at the foramen spinosum and divides into frontal (anterior) and parietal (posterior) branches 15 to $30 \mathrm{~mm}$ anterolateral to the foramen spinosum. The groove for the frontal branch also divides behind the lateral part of the greater wing into a lateral branch, which passes laterally and posteriorly across the pterion, and a medial branch, which courses medially along the lower surface of the sphenoid ridge. Therefore this point is an important landmark for anterior branch of middle meningeal artery, Broca's motor speech area in the left, insula, the lateral cerebral fissure, for the pathologies of optic nerve, orbit, sphenoidal ridge and for the anterior circulation aneurysms and tumours $[22,6]$.

Jinulu et al [27] in their study stated that the middle meningeal artery (MMA) is a very important artery in neurosurgery. Many diseases, involve the MMA i.e. dural arteriovenous fistula, aneurysm, traumatic arteriovenous fistula, recurrent chronic subdural hematoma, migraine and meningioma, in these diseases, the lesions occur in either the MMA itself or its branch or the MMA is used as the pathway to treat the lesions. Aneurysms in the MMA can be treated by endovascular or surgical removal. For recurrent chronic subdural hematoma burr hole irrigation and drainage, MMA embolization is usually attempted So, in this study we tried to find the relation of the anterior branch of middle meningeal artery which in close relation with the internal surface of pterion; we found that the stellate variety had both farthest and nearest distances to the frontal branch of MMA.

In our study the Sphenoparietal was the commonest type of pterion both bilaterally as 
well as unilaterally. Tis resembles the data of the above-mentioned studies also. Epipteric bone were found mostly unilaterally that too more on left side. average distance of pterion from FZ suture \& ZA. Average distance from FZ suture on both sides were $2.8 \mathrm{~cm}$. its distance from ZA was little different on both sides being $3.5 \mathrm{~cm}$ on right $\& 3.4 \mathrm{~cm}$ on left. Average distance of MMA from mid-point of pterion measured from inside of cranial cavity. It was measured to be $4.9 \mathrm{~mm}$ on right side $\& 5.13 \mathrm{~mm}$ on left side.

\section{CONCLUSION}

Sphenoparietal type was most common to be present bilaterally as well as unilaterally. Epipteric bones were found more in Sphenoparietal type unilaterally \& bilaterally. The anterior branch of MMA was both closest \& farthest in in Stellate type of pterion

\section{Author Contributions:}

Vimal Gupta - helped in practical work

Anshu Sharma- conception and draft

Kanchan Kapoor - facilitated the work

\section{Conflicts of Interests: None}

\section{REFERENCES}

[1]. U Ukoha, CK Oranusi, JI Okafor1, OO Udemezue, AE Anyabolu, TC Nwamarachi1. Anatomic study of the pterion in Nigerian dry human skulls. Nigerian Journal of Clinical Practice. Jul-Sep 2013; 163:325-28

[2]. Ersoy M, Evliyaoglu C, Bozkurt MC, Konuksan B, Tekdemir I, Keskil IS. Epipteric bones in the pterion may be surgical pitfall. Minim Invasive Neurosurg.2003; 46: 364-5.

[3]. Fahlbusch R, Schott W. Pterional surgery of meningiomas of the tuberculum sellae and planumsphenoidale. Surgical results with special consideration of ophthalmological and endocrinological outcomes. J Neurosurg.2002;96: 235-43.

[4]. Feng WF, Qi ST, Huang SP, Huang LJ. Surgical treatment of anterior circulation aneurysm via pterion keyhole approach. Di Yi Jun Yi Da Xue Xue Bao.2005;25: 546-8.

[5]. Yasargil M. Interfascial pterional (frontotem porosphenoidal) craniotomy. Microneurosurg. 1984.1. 217-20

[6]. Yasargil M Fox J, Ray M. The operative approach to aneurysms of the anterior communicating artery. Adv Tech Stand Neurosurg.1975; 2:113-7

[7]. Saxena RC, Bilodi AK, Mane SS, Kumar A. Study of pterion in skulls of Awadh area-in and around Lucknow. Kathmandu Univ Med J.2003; 1(1): 32-3
[8]. Morriss-Kay GM, Wilkie AO. Growth of the normal skull vault and its alteration in craniosynostosis: insights from human genetics and experimental studies. J Anat. 2003; 207:637-53

[9]. Cohen M, and MacLean R (2005) Craniosynostosis: Diagnosis, Evaluation, and Management. New York: Oxford Press.

[10]. Enlow D, and Hans M (1996) Essentials of Facial Growth. Ann Arbor: Needham Press

[11]. Hall B (2005) Bones and Cartilage: Developmental Skeletal Biology San Diego: Academic Press.

[12]. Moore K, and Persaud T (2007) Before We Are Born: Essentials of Embryology and Birth Defects. St. Louis: Saunders.

[13]. Sperber G Craniofacial Development. Shelton: (2001) People's Medical Publishing House.

[14]. Coussens AK, van Daal A. Linkage disequilibrium analysis identifies an FGFR1 haplotype-tag SNP associated with normal variation in craniofacial shape. Genomics 2005; 85:563-73.

[15]. Coussens AK, Wilkinson CR, Hughes IP, Morris CP, van Daal A, Anderson PJ, and Powell BC. Unravelling the molecular control of calvarial suture fusion in children with craniosynostosis. BMC Genomics. 2007; 8: 458.

[16]. Passos-Bueno MR, Serti Eacute AE, Jehee FS, Fanganiello R, and Yeh E. Genetics of craniosynostosis: genes, syndromes, mutations and genotypephenotype correlations. Front Oral Biol.2008; 12:107-43.

[17]. Mooney MP, Burrows AM, Smith TD, Losken HW, Opperman LA, Dechant J, Kreithen AM, Kapucu R, Cooper GM, Ogle RC, and Siegel MI Correction of coronal suture synostosis using suture and dura mater allografts in rabbits with familial craniosynostosis. Cleft Palate Craniofac J. 2001; 38:20625.

[18]. Herring SW. Mechanical influences on suture development and patency. Front Oral Biol.2008; 12: 41-56.

[19]. Fong KD, Nacamuli RP, Loboa EG, Henderson JH, Fang TD, Song HM, Cowan CM, Warren SM, Carter DR, Longaker) 'Equibiaxial tensile strain affects calvarial osteoblast biology'. J Craniofac Surg.2003; 14: 348-55.

[20]. Wu YD, Chien CH, Chao YJ, Yu JC, and Williamson MA. Fourier analysis of human sagittal sutures. Cleft Palate Craniofac J. 2007; 44: 482-93.

[21]. Saxena SK, Jain SP, Chowdhary DS. A comparative study of pterion formation and its variations in the skulls of Nigerians and Indians. Anthropol Anz. 1988; 46:75-82.

[22]. G Matsumura, K Kida, R Ichikawa, G Kodama. Pterion and epipteric bones in Japanese adults and fetuses, with special reference to their formation and variations. Kaibogaku Zasshi. 1991 Oct;66(5):462-71.

[23]. Asala SA, Mbajiorgu FE. Epigenetic variation in the Nigerian skull: sutural pattern at the pterion. East Afr Med J.1996;73(7): 484-6. 
[24]. Mwachaka PM, Hassanali J, Odula P. Sutural morphology of the pterion and asterion among adult Kenyans. Braz J Morphol Sci .2009; 26: 4-7.

[25]. Praba AMA, Venkatramaniah C. Morphometric Study of different types of Pterion and it's relation with middle meningeal artery in dry skulls of Tamil Nadu. JPBMS.2012; 21 (04): 1-4.

[26]. Merland JJ, Theron J, Lasjaunias P, Moret J. Meningeal blood supply of the convexity. J Neuroradiol;1997; 4:129-74.
[27]. Jinlu Yu, Yunbao Guo, Baofeng Xu, Kan Xu. Clinical importance of the middle meningeal artery: A review of the literature. Int. J. Med. Sci. 2016;133(10): 790-99.

How to cite this article:

Vimal Gupta, Anshu Sharma, Kanchan Kapoor. Pterion: Morphometry and Surgical Significance. Int J Anat Res 2022;10(1):8197-8205.

DOI: $10.16965 /$ ijar.2021.185 